\title{
The effect of a preoperative informative video on the perception of pain in youths undergoing third molar extraction: a randomized clinical trial *
}

\author{
O efeito de vídeo informativo pré-operatório na percepção de dor em jovens submetidos à \\ exodontia de terceiros molares: estudo randomizado
}

Maylu Botta Hafner ${ }^{1}$, Juliana Zanatta ${ }^{1}$, Gustavo Sattolo Rolim¹, Antônio Bento Alves de Moraes ${ }^{1}$, Angélica Maria Bicudo Zeferino²

${ }^{*}$ Received from School of Dentistry of Piracicaba, State University of Campinas, Campinas, SP, Brazil.

\section{ABSTRACT}

BACKGROUND AND OBJECTIVES: The extraction of the third molar is an invasive procedure and is potentially traumatic for the patient. Preparatory procedures may be used for the management of pain and emotional responses, resulting in a better recovery process for patients. The aim of the study evaluates the effects of a preparatory procedure using an animated informative video on post-surgical pain responses after third molar extraction on youths during the postoperative follow-up.

METHODS: 140 patients undergoing third molar extraction were randomly divided into two groups: control (CG) and experimental (EG). For pain assessment, the short-form McGill pain questionnaire was given once before the procedure and four times after the surgery, and the amount of postoperative analgesic consumption was recorded. The informative video was presented to the EG after the first assessment. For data analysis, ANOVA and Tukey tests $(\mathrm{p} \leq 0.05)$ were used. Data analysis indicated that the EG patients reported reduced pain perception for all pain indexes. RESULTS: Significant between-group differences were observed for Sensory and Affective Rank Pain Indexes (PRI-S and PRI-A, respectively), as well as for Global Assessment, at stages 2, 3 and $4(p=0.0001 ; p=0.0027 ; p=0.0001)$. For Present Pain Intensity, a significant difference between groups was observed $(\mathrm{p}=0.0004)$ at stages 3, 4 and 5. The postoperative consumption of analgesics was lower in the EG $(\mathrm{p}=0.0001)$, indicating higher medicine consumption by CG patients.

CONCLUSION: The results suggest that the preoperative informative video effectively reduced pain perception and the consumption of analgesics.

Keywords: Behavioral management, Pain, Pre-surgical education.

1. State University of Campinas, Dentistry School of Piracicaba, Piracicaba, SP, Brazil.

2. State University of Campinas, School of Medical Sciences, Campinas, SP, Brazil.

Submitted in June 28, 2013.

Accepted for publication in October 16, 2013.

Conflict of interests: none.

Correspondence to:

Maylu Botta Hafner

Av. Limeira, 901 - Bairro Areiâo

13414-903 Piracicaba, SP.

E-mail: mayluhafner@yahoo.com.br

(c) Sociedade Brasileira para o Estudo da Dor

\section{RESUMO}

JUSTIFICATIVA E OBJETIVOS: A exodontia de terceiros molares é um procedimento invasivo e potencialmente traumático. Procedimentos preparatórios podem ser usados para manuseio da dor e de respostas emocionais, resultando em uma melhor recuperaçáo dos pacientes. O objetivo deste estudo foi avaliar os efeitos de um vídeo de animação informativo em respostas de dor após exodontia de terceiro molar em jovens.

MÉTODOS: Neste estudo, 140 pacientes submetidos a exodontia de terceiro molar foram randomizados em dois grupos: controle (GC) e experimental (GE). Para avaliação da dor foi utilizado o Questionário de Dor McGill, forma reduzida. Essa avaliaçáa foi realizada uma vez antes do procedimento cirúrgico e quatro vezes após. Foi também registrada a quantidade de analgésicos consumidos após exodontia. $\mathrm{O}$ vídeo informativo foi apresentado ao GE após a primeira avaliação. Foram utilizados os testes ANOVA e Tukey para análise de dados $(\mathrm{p} \leq 0,05)$.

RESULTADOS: A análise mostrou que o GE relatou diminuição de todos os índices de dor. Diferença significativa entre os grupos foi observada nos Índices de Estimativa de Dor Sensorial e Afetiva (PRI-S e PRI-A), como na Avaliaçáo Global de Experiência de Dor nas fases 2, 3 e $4(\mathrm{p}=0,0001 ; \mathrm{p}=0,0027$; $\mathrm{p}=0,0001$ ). Para a Intensidade de Dor Presente (PPI) foi observada diferença significativa entre os grupos $(\mathrm{p}=0,0004)$ nas fases 3,4 e 5 . O consumo pós-operatório de analgésico foi menor no GE ( $\mathrm{p}=0,0001)$, indicando um maior consumo de medicamento para o GC.

CONCLUSÁO: Os resultados sugerem que o vídeo de informação pré-operatório efetivamente reduziu a percepção de dor e o consumo de analgésicos.

Descritores: Dor, Educação pré-cirúrgica, Manuseio de comportamento.

\section{INTRODUCTION}

The surgical procedure for extracting a third molar is usually performed by oral and maxillofacial surgeons and is associated with pain and/or discomfort ${ }^{1}$. Poor pain outcomes associated with this type of surgery should be improved. Indeed, Study ${ }^{2}$ suggested that pain relief can help the patient by reducing suf- 
fering, hospitalization time and treatment costs.

An integrated approach to pain relief includes administration of analgesic medications and pre-surgical education using cognitive and/or behavioral interventions. Pre-surgical education, also characterized as a preparatory procedure, aims to reduce anxiety responses and establish the patients' adaptive responses to the surgical intervention and postoperative stage ${ }^{3}$.

Preparatory procedures for invasive treatments may involve strategies such as informative videos ${ }^{4}$, internet programs ${ }^{5}$, informative leaflets ${ }^{6}$, video and conversations conducted by trained professionals ${ }^{7}$, among others. These strategies are also highlighted by the $\mathrm{WHO}^{8}$ as effective methods for the psychological preparation of patients for invasive procedures.

The effect of informative videos on postoperative outcomes was assessed in different areas of medicine, and the results showed that this strategy improves anxiety levels and patient satisfaction $^{3}$ and reduces the need for administration of postoperative analgesics? .

The video may contain (a) clinical information describing the technical procedure to be executed; (b) sensory information that discusses what the patient may feel; and (c) behavioral information that explains what the patient can do and what kind of responses are expected. According to study ${ }^{10}$, this information familiarizes the patients with the clinical routines and reduces the precedent anxiety.

To date, the effect of preoperative information videos on the outcome of third molar extraction surgeries has not been evaluated. Study ${ }^{10}$ referred to studies that used other cognitivebehavioral procedures, such as the provision of informative booklets, as preparatory strategies for this surgical procedure. As the extraction of the third molar is a common surgical technique with a relatively short period of recovery, we investigated the effects of a preoperative animated informative video on post-surgery pain responses reported in youths during the postoperative follow-up.

This study aims evaluate the effects of a preparatory procedure using an animated informative video on post-surgical pain responses after third molar extraction on youths during the postoperative follow-up.

\section{METHODS}

This study included 162 patients attending the Surgery Unit at Piracicaba Dental School, State University of Campinas (UNICAMP), for the extraction of at least one third molar in one dental session. The patients lived in Piracicaba and the surrounding municipalities of São Paulo, Brazil, and their mean age was $19.32 \pm 2.83, \min =14, \max =24$ ).

The patients agreed to participate in the research under the conditions specified by the Free and Clarified Consent Term (FCCT). All ethical guidelines were followed by all researchers. The patients signed the FCCT and, when younger than 18 years old, the term was signed by their legal guardian. Twenty two patients were excluded from this study because they missed the appointment on the day of data collection, failed to complete questionnaires during the data collection or withdrew their consent.

Patients were randomly distributed between the experimental group (EG; individuals who watched the informative video) and the control group (CG; individuals who did not watch the informative video). Randomization of 162 patients was performed by one researcher using specific software found at <http://www.randomizer.org >. These patients were treated by 12 surgeons the Surgery Unit UNICAMP. The patients were distributed equally among surgeons.

Before the first assessment, each patient had an individual interview to characterize their health status and health behaviors, including the use of medications (regular and presurgical) and their history of oral surgery.

Pain measurements were taken from all patients of both groups in five stages: (1) immediately before surgery (immediate pre-surgery); (2) immediately after surgery (immediate post-surgery); (3) one day after extraction (mediate post-surgery I); (4) three days after extraction (mediate post-surgery II); and (5) seven days after extraction (before the appointment for suture removal).

For each stage, the short-form McGill pain questionnaire was given to assess pain ratings. At stage 3, the patients answered the McGill questionnaire at their houses by telephone at prearranged hours. The self-report of medication use for postoperative pain relief over the 7 days of recovery was also recorded.

The Brazilian version of the short-form McGill pain questionnaire is based on the original English language questionnaire (short form) developed by Melzack ${ }^{11}$ and is the first multidimensional scale for pain assessment capable of providing quantitative measures that can be evaluated statistically ${ }^{12}$. In Brazil, Pimenta and Teixeira ${ }^{13}$ translated and validated this questionnaire. The McGill Pain Questionnaire assesses not only pain intensity, but also sensory and affective aspects of the pain experience. The questionnaire also assesses the pain felt at the time of its application and is divided into four parts: Sensory Pain Rank Index (PRI-S), Affective Pain Rank Index (PRI-A), Present Pain Intensity (PPI) and Global Assessment of Pain Experience.

PRI-S is composed of 11 descriptors of the sensory experience of pain, and PRI-A is composed of 4 descriptors of the affective experience of pain. Each descriptor provides indicators related to pain intensity and patients are asked to assign values ranging from 0 to 3 . The indicators are (0) none, (1) mild, (2) moderate and (3) severe. PPI is composed of a visual analogue scale (VAS) consisting of a straight line of $100 \mathrm{~mm}$, with a tag at each end of the indicators: "no pain" and "worst possible pain". The Global Assessment is composed of 6 indicators that describe the pain experience: "no pain", "mild", "uncomfortable", "distressing", "horrible" and "excruciating". Analgesic use was monitored during the first seven days of post-surgical recovery by a form completed by the patient each time they took their medication. At stage 2 (immediate post surgery), the patient received a card with a treatment schedule (containing the dates of telephone calls - stage 3 - and of return visits - stages 4 and 5) and a framework for 
registration of medication consumption. On this card, patients were instructed to draw an " $\mathrm{X}$ " each time they took pain medication prescribed by the surgeon, thus providing an indirect measurement performed by the patients without the aid of any researcher.

Animated informative video: The 5-min and 6-sec video was developed by the researchers conducting this study and financially supported by the Development Foundation of Campinas - UNICAMP. Four steps were considered: (a) criteria formulation; (b) objective; (c) script; and (d) video development. The following criteria were used: target audience; length of the video; images; technique; language; and content. The aim of the video was to provide the patients with technical information about the surgical procedure and sensory information. The video shows a third molar figure as the leading character and uses simple and direct language, In each frame, the procedures and sensory information are presented by a narrator, and corresponding photos and drawings are shown. The video also contains information about the formation and location of the third molars, the site of care, the professionals involved, the necessary procedures, ways to communicate with health professionals, and the use of distraction techniques during surgery. Additionally, the video addresses sensations patients may feel following surgery and provides information on proper postoperative care.

Participants in the EG were individually introduced to the video after the first evaluation of pain. Patients watched the video on a laptop using headphones while they were seated in a dental chair at the surgical clinic prior to the surgery. Information about the surgical procedures and postoperative period was provided only during the video.

To ensure that the researchers were not aware of which group each patient belonged, some researchers stayed with the patients until the moment before surgery (stage 1), and other researchers accompanied the patients through the remaining stages (immediate and mediate post surgery).

\section{Data analysis}

To analyze the data obtained in the McGill Pain Questionnaire and the data on administration of analgesics, we used an analysis of variance (ANOVA). Rank transformation was employed due to the non-normal distribution of the results and to reduce the asymmetry and variability of the data ( $p$ value $\leq 0.05)$.

For analyses between groups, multiple comparison tests were performed (Tukey tests for intergroup analysis (control and experimental), and contrast tests for analysis among the five stages of intra-group evaluation (control or experimental) (pvalue $\leq 0.05$ ).

For categorical variables (number of extractions), associations between groups were analyzed using Chi-squared tests, and when the expected values were smaller than 5, we used Fisher's Exact test. The level of significance was 5\% (i.e., a p-value $\leq 0.05$ ).

The present study was approved by the Ethics Committee in Research (Protocol no 024/2008).

\section{RESULTS}

The results are presented in tables showing the frequency of dental extractions performed and the average use of medicines by patients in each group. The average scores obtained from the McGill Questionnaire at each of the five stages of pain assessment for each group are also shown.

Table 1 shows the number of patients per group, the relative frequency of those who had a history of surgical treatment and the number of teeth extracted during the extraction per group. All patients included in this study underwent only one extraction session.

Table 1. Number of patients in each group and the relative frequency of patients with dental surgical experience and the relative frequency of dental extractions performed in dental session

\begin{tabular}{lccc}
\hline & $\begin{array}{c}\text { Control } \\
\text { group } \\
(\mathrm{n}=70)\end{array}$ & $\begin{array}{c}\text { Experimental } \\
\text { group } \\
(\mathrm{n}=70)\end{array}$ & $\mathrm{p}$ value \\
\hline With previous extraction (\%) & 30 & 35.8 & 0.4717 \\
Extraction 1 element (\%) & 14.3 & 14.3 & \\
Extraction 2 elements (\%) & 50 & 54.3 & \\
Extraction 3 elements (\%) & 10 & 5.7 & \\
Extraction 4 elements (\%) & 25.7 & 25.7 & 0.8154 \\
\hline
\end{tabular}

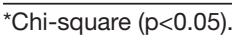

As shown in table 1, significant differences between groups were not observed for history of dental surgery or the number of extracted teeth. It is noteworthy that $50 \%$ of participants in each group had undergone extraction of 2 third molars. Extraction of 3 third molars occurred less frequently (less than $10 \%$ of surgeries). The percentage of patients by number of extractions was similar in both groups. Specifically, the groups were homogeneous in terms of previous surgical experience and the number of teeth extracted in a dental session, as verified by Chi-squared tests.

Figure 1 shows four graphs of responses to the McGill Questionnaire pain indexes, corresponding to the averages for each of the 5 stages of assessment: PRI-S, PRI-A (upper left and right graphs, respectively), PPI and Global (lower left and right graphs, respectively). For all graphs, the solid line (with filled triangles) refers to average values from the CG, and the dashed line (with unfilled squares) refers to the average values of the EG. The vertical axis shows the mean values, whereas the horizontal axis shows the stages of each pain assessment. Below each horizontal axis there are three different lines. The first, named "Group", represents the intergroup analysis at each stage (i.e., a significant difference between the CG and EG).

The second and third lines indicate the intra-group analysis. Values for the CG (second line) and the EG (third line) are given in parentheses for each stage of assessment, and significant differences between stages are indicated. For example, if the values for stage 1 were significantly different from those for stages 3 and 5, stages 3 and 5 are written below stage 1 . The results of figure 1 are presented according to pain indexes (PRI-S, PRI-A, PPI, and Global). 

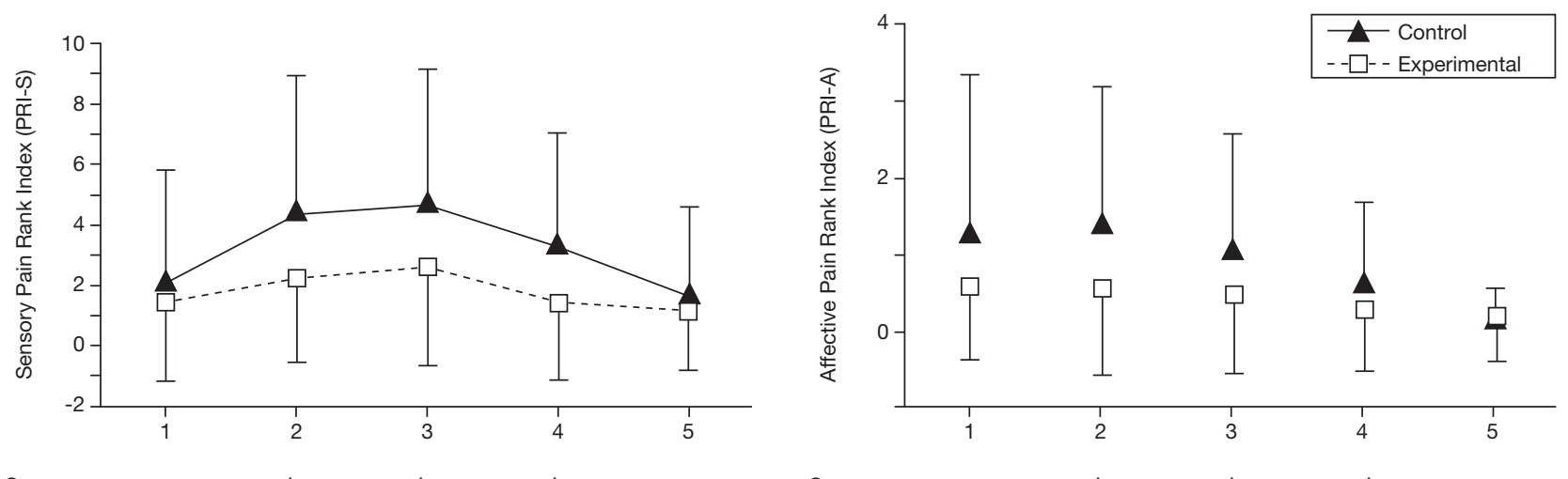

$\begin{array}{llll}\text { Group } & \star & \star & \star \\ \text { IA /control }(2,3,4) & (5) & (4,5) & (5) \\ \text { IA Esperimental }(2,3) & (4,5) & (4,5) & \end{array}$

Group

IA Esperimental $(2,3) \quad(4,5) \quad(4,5)$

IA /control (5)

IA Esperimental $(4,5)$

$(3,4,5)$

(5)

$(5)$
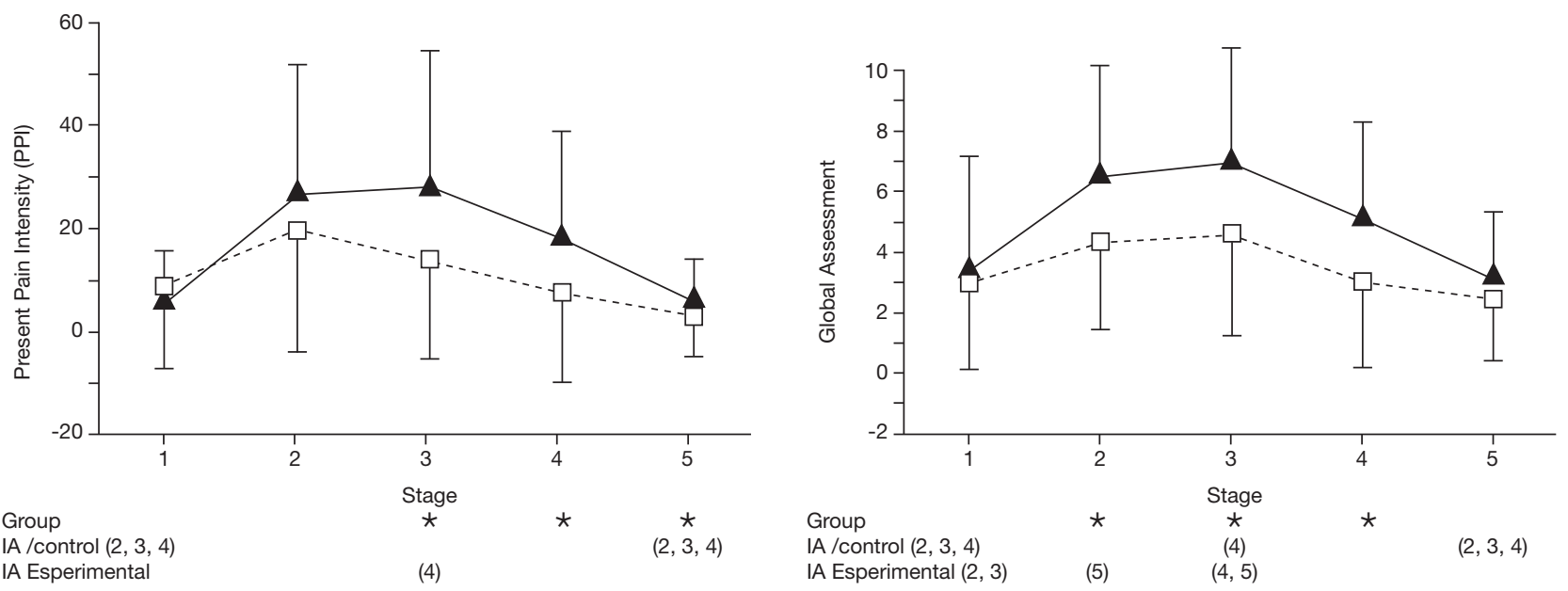

Figure 1. Averages and standard deviation of index of pain assessed by the short-form McGill pain questionnaire (PRI-S, PRI-A, PPI, Global Assessment), at the five stages of data collection of the Control and Experimental Groups

Captions: IA Experimental: Intra-group assessment of the Experimental Group. IA Control: Intra-group assessment of the Control Group. In the 'Group', the asterisk indicates statistically significant difference for the assessed stage (Tukey test). In the intra-group assessment, the numbers in parentheses indicate the stage(s) that differs from this stage (Contrast test). The value of significance adopted was $\mathrm{p} \leq 0.05$.

PRI-S variable - Figure 1 (PRI-S) shows that both groups presented an increase in the average values from the first to the third stage, followed by a decrease in the fourth and fifth stages. The results of the analysis of variable PRI-S reveal a significant difference between the groups $(\mathrm{p}=0.0001)$ at stages 2, 3 and 4. Participants who watched the informative video presented lower scores than those in the control group during these three stages of treatment.

For the intra-group analysis of the control group, the average of stage 1 was significantly different from the average of stages 2,3 and 4 . The average of stage 2 differed from the average of stage 5 . In this same analysis, the average of stage 3 differed from the average of stages 4 and 5, whereas the average of stage 4 differed from the average of stage 5 . For intra-group analysis of the EG, the average of stage 1 significantly differed from those of stages 2 and 3 . The average of stage 2 differed from the averages of stages 4 and 5 . The average of stage 3 differed from the averages of stages 4 and 5 .

The report of pre-surgical pain by both groups was not significantly different. However, there was a difference during the immediate post-surgery period (stage 2). This suggests that the video was effective in reducing sensory pain at this stage for patients in the EG. This difference was also observed one day after surgery (stage 3 ) and three days after surgery (stage 4). On the day of suture removal, no significant differences in pain were observed between the groups. However, a decrease in the values of sensory pain was observed in the CG.

PRI-A variable - For the PRI-A variable, there was a statistically significant difference between the groups $(p=0.0027)$ at stages 2, 3 and 4, whereas the EG participants reported lower pain scores for this index. This data agrees with the results obtained using the PRI-S.

In the intra-group analysis of the CG, the averages of stages 1 , 3 and 4 were different compared with the average of stage 5 . 
Specifically, the lowest averages were reported at stage 5 . The average of stage 2 was significantly different from the averages of stages 3, 4 and 5. For the EG, the intra-group analysis indicated that the average of stage 1 was significantly different from the averages of stages 4 and 5 .

The report of pre-surgical pain for both groups did not differ. As in the PRI-S, we observed differences at the immediate post-surgery period (stage 2 ). This suggests that the video was effective in reducing affective pain, which was felt at this stage by patients of the EG. These differences as well in sensory pain were observed one day (stage 3 ) and three days after surgery (stage 4). On the day of suture removal, no differences between groups were observed, although the CG reported decreased affective pain.

PPI variable - For the analysis of the PPI variable, a statistically significant difference between the groups $(\mathrm{p}=0.0004)$ at stages 3, 4 and 5 was observed. Participants of the EG reported lower pain scores in this index at these stages.

For the intra-group analysis of the CG, the averages of stages 1 and 5 were significantly different from the averages of stages 2, 3 and 4. Specifically, higher values were reported at stage 4. For the EG, the average of stage 3 differed from the average of stage 4. Specifically, higher values were reported at stage 3 . Reduced pain was reported by patients who watched the informative video. The reports of pain during the pre-surgical and immediate post-surgery periods in both groups did not differ. The EG reported lower pain experience compared to CG the day after surgery (stage 3 ). This suggests that the video was effective in reducing this pain index in patients of the EG. Unlike differences for the previous indexes, the differences were also observed 7 days after surgery (stage 5).

Global assessment variable - Significant differences between the groups ( $\mathrm{p}=0.0001)$ were observed at stages 2,3 and 4 . Specifically, the pain scores reported by the EG at these stages were lower than the scores reported by the CG.

For the intra-group analysis of CG, stages 1 and 5 were different from the averages of the three other stages. The average of stage 3 differed from the average of stage 4 . For the EG, the average of stage 1 significantly differed from the averages of stages 2 and 3, and the average of stage 2 differed from the average of stage 5 . The average of stage 3 differed from the averages of stages 4 and 5 .

The report of pre-surgical pain in both groups did not differ. A difference in pain during the immediate post-surgery period (stage 2) was observed. This difference was also observed the day after surgery (stage 3 ) and three days after surgery (stage 4). These results are similar to those obtained using the PRI$S$ and PRI-A. On the day of suture removal, no differences between groups were observed. However, a decrease in values for the CG was observed, suggesting that the video effectively reduced the global index of pain for patients in the EG.

Table 2 shows the average (and the calculated standard deviation) administration of medication for post-surgical pain and of the anesthetic cartridge throughout the extraction. The first line shows the average anesthetic cartridge (lidocaine HCI $2 \%+$ epinephrine 1:100.000) applied throughout the
Table 2. Average frequency and standard deviation of the use of anesthetic ampoule during surgery, and average frequency and standard deviation of the consumption of pain medication in postoperative period

\begin{tabular}{lccc}
\hline & $\begin{array}{c}\text { Control } \\
\text { group }\end{array}$ & $\begin{array}{c}\text { Experimental } \\
\text { group }\end{array}$ & p value \\
\hline Anesthetic ampoule & $4.86 \pm 2.01$ & $5.01 \pm 1.81$ & 0.5911 \\
Pain medications & $10.8 \pm 5.68$ & $6.63 \pm 5.31$ & $0.0001^{*}$ \\
\hline${ }^{*}$ Chi-square $(\mathrm{p}<0.05)$. & & &
\end{tabular}

surgery in each group. The second line shows the administration of pain medication (dipyrone; $500 \mathrm{mg}$ ) in each group and the statistical analysis comparing these groups. No betweengroup differences in the number of anesthetics cartridges used was observed $(\mathrm{p}=0.5911)$, indicating homogeneity between the groups. The analysis of analgesic administration during the 7 days of post-operative recovery showed statistically significant differences between groups $(\mathrm{p}=0.0001)$, indicating a much greater consumption of pills for the CG.

\section{DISCUSSION}

The results of this study indicate that the preparatory procedure of an informative video of technical and sensory information reduced the perception of post-operative pain as assessed by the short-form McGill Pain Questionnaire. In addition to the reduced perception of pain, the analgesic intake after surgery was reduced in the patients who watched the video.

This study assessed the effects of providing sensory and technical information before the surgery on pain responses, medication intake and pain identification. Van Wijk et al. ${ }^{10}$ investigated the impact of this information provided through booklets (folders) on patients who underwent third molar extraction. The authors indicated that patients preferred receiving "full information" about the routine techniques used during the procedure and the possible sensations that may be felt as a result of the procedure rather than receiving "basic technical information". A video was used to disseminate what Wijk calls "full information," which was found to decrease pain indexes and analgesics consumption following third molar extractions.

Vallerand, Vallerand and $\mathrm{Heft}^{14}$ studied the effect of disseminating information through leaflets on pain outcomes following third molar extraction in 37 patients. One group of patients received basic technical information for post-operative care, and the other received full information about postoperative care, complications, sensations and analgesic consumption. Pain was assessed using a Visual Analog Scale given every three hours during the first 45 post-operative hours. Patients who received full information reported less pain 1218 hours and 24 hours after surgery. However, no differences in analgesic consumption were observed. These authors emphasized that the set of information about the procedure, the sensations and the post-operative care were responsible for the reduction in pain reports and did not increase consumption of analgesics. A limited number of patients was assessed 
and quantification of pain was based on a single index (Visual Analogue Scale), though pain is considered to be a multidimensional phenomenon. Nonetheless, that study showed similar effects of preoperative education on post-operative pain to those of the present study. Indeed, the information offered in their booklet was similar to that offered in our video, which might account for the similar results.

The findings of the two studies discussed above (van Wijik et al. ${ }^{10}$; Vallerand, Vallerand and $\mathrm{Heft}^{14}$ ) corroborate those of the present study. Indeed, these studies suggest that the dissemination of technical and sensory information to patients before surgery is perceived positively and contributes to improved postsurgical recovery. Thus, any informative approach using leaflets or videos may be effective as long as it contains 'complete' information on the technical, procedural, sensorial and behavioral aspects of the surgical experience. Indeed, the use of leaflets may be more applicable because they are less costly. In a study assessing the effectiveness of disseminating information using a video, Bytzer and Lindeberg ${ }^{4}$ reported different results from those obtained in this study. Bytzer and Lindeberg assessed the effects of an informative video describing the exam procedure only on outcomes following colonoscopy in 162 patients. Pain was measured following the invasive procedure using the visual analog scale (VAS), and the consumption of analgesics (fentanyl). No significant differences in pain scores recorded after the invasive procedure were observed between the group that watched the informative video and the group that did not. In terms of the consumption of analgesics, Bytzer and Lindeberg observed greater consumption among patients who watched the video, although this difference was not significant. The results may be attributed to the limited scope of content provided by the informative video, which educated patients on the technical aspects of the invasive procedure only, which is significantly different from the video used in the current study. Thus, it is possible that the dissemination of technical information alone may not benefit the patients.

Zieren, Menenakos and Mueller ${ }^{15}$ assessed the influence of an informative video on the reports of patients' quality of life during the post-operative stage of inguinal hernia surgery. The video showed the technical and sensory aspects involved in hernia surgery, including information about post-operative care and sensations that may be experienced. Changes in quality of life were assessed throughout the year after the surgery using the Quality of Life Scale (SF-36-short form). The findings showed that patients who watched the video were less affected than those who did not in terms of both physical and psychological functioning. For pain specifically, no significant differences were observed during the immediate postsurgery period, although the score was lower for the group that watched the video. These results suggest a tendency for informative videos to prepare patients to undergo invasive procedures. Because the information disseminated in study was similar to that of the current study, it is reasonable to hypothesize that the information contained in the video was a determining factor in improving the quality of life outcomes.
In accordance with the current results, reduced consumption of analgesics following preoperative education was reported by Doering, Katzlberger and Rumpold 9 . These authors assessed the effect of an informative video on outcomes following hip replacement surgery in 100 patients. In that study, the video showed sensory and technical data and emphasized the patient's perception of pain during the invasive procedure. Among other variables, the authors recorded reports of postoperative pain and analgesic consumption in two groups (one that watched the video and other that did not) for four days after the procedure. To assess pain, the authors used the VAS immediately following surgery and once a day for each of four post-operative days, resulting in a total of five measurements. The authors reported no significant differences between the groups in their reports of pain. However, the group that watched the video consumed fewer analgesics over the four post-operative days. Because the VAS is just one of the many indices included on the McGill questionnaire, that study may have been less sensitive to differences between groups than the current study, which may explain the different results. In addition, the surgical procedures and the degree of physical impairment following the procedures greatly differ, which may also explain the different results obtained in the current study. Although several studies have investigated postoperative analgesic use, it is important to note that this outcome variable is limited because it is an indirect measurement and is self-reported. An alternative approach would be to monitor medication use through researcher supervision by counting the number of analgesics patients take during post-operative periods.

\section{CONCLUSION}

The results of this study indicate that informing patients about the impending surgical procedure by means of audiovisual features that include technical, sensory and behavioral information may be effective in reducing pain and pain responses following an invasive procedure.

The use of animated informative videos as preparatory procedures for invasive third molar extractions is effective in decreasing the pain reported. Additionally, these videos may reduce the post-operative consumption of analgesics. The use of similar informative videos appears to be effective in other invasive procedures and may be an important component of preoperative preparations. However, this effectiveness requires further study to determine the importance of the offered information in meeting the patients' needs.

\section{ACKNOWLEDGEMENTS}

We thank the Surgical Service, Faculty of Dentistry of Piracicaba (FOP), UNICAMP, which gave us professionals to collaborate with, as well as physical space for the research, and the Development Foundation of Campinas, UNICAMP, for financial support for the production of the informative video. We also thank the researchers that participated in the data collection and all the patients who agreed to participate. 


\section{REFERENCES}

1. van Wijk AV, Lindeboom J. The effect of a separate consultation on anxiety levels before third molar surgery. Oral Surg Oral Med Oral Pathol Oral Radiol Endod. 2008;105(3):303-7.

2. Keulers BJ, Scheltinga MR, Houterman S, Van Der Wilt GJ, Spauwen PH. Surgeons underestimate their patients' desire for preoperative information. World J Surg. 2008;32(6):964-70.

3. Ruffinengo C, Versino E, Renga G. Effectiveness of an informative video on reducing anxiety levels in patients undergoing elective coronarography: an RCT. Eur J Cardiovasc Nurs. 2009;8(1):57-61

4. Bytzer P, Lindeberg B. Impact of an information of an information video before colonoscopy on patient satisfaction and anxiety: a randomized trial. Endoscopy. 2007;39(8):710-4

5. O'Conner-Von S. Preparation of adolescents for outpatient surgery: using an internet program. AORN J. 2008;87(2):374-98.

6. Sjöling M, Nordahl G, Olofsson N, Asplund K. The impact of preoperative information on state anxiety, postoperative pain and satisfaction with pain management. Patient Educ Couns. 2003;51(2):169-76.

7. Zanatta J, Hafner MB, Rolim GS, Moraes AB. Informação prévia face a face e controle da dor em exodontia de terceiros molares. Rev Dor. 2012;13(3):249-55.

8. Horne DJDL, Vatnamalis P, Careri A. Preparation for invasive procedures: behavioural science learning modules. WHO, 1993.

9. Doering S, Katzlberger F, Rumpold G, Roessler S, Hofstoetter B, Schatz DS, et al Videotape preparation of patients before hip replacement surgery reduces stress. Psychosom Med. 2000;62(3):365-73.

10. van Wijk AJ, Buchanan H, Coulson N, Hoogstraten J. Preparatory information for third molar extraction: does preference for information and behavioral involvement matter? Patient Educ Couns. 2010;79(1):94-9.

11. Melzack R. The short-form McGill pain questionnaire. Pain. 1987;30(2):191-7.

12. Maiani G, Sanavio E. Semantics of pain in Italy: the Italian version of the McGill Pain Questionnaire. Pain. 1985;22(4):399-405.

13. Pimenta CA, Teixeira MJ. Questionário de dor McGill: proposta de adaptação para a língua portuguesa. Rev Bras Anestesiol. 1997;47(2):177-86.

14. Vallerand WP, Vallerand AH, Heft M. The effects of postoperative preparatory information on the clinical course following third molar extraction. J Oral Maxillofac Surg. 1994;52(11):1165-71.

15. Zieren J, Menenakos C, Mueller JM. Does an informative video before inguinal hernia surgical repair influence postoperative quality of life? Results of a prospective randomized study. Qual Life Res. 2007;16(5):725-9. 